\title{
Event Marketing and Attitude Changes
}

\author{
Gerd Nufer \\ Reutlingen University, ESB Business School, Reutlingen, Germany
}

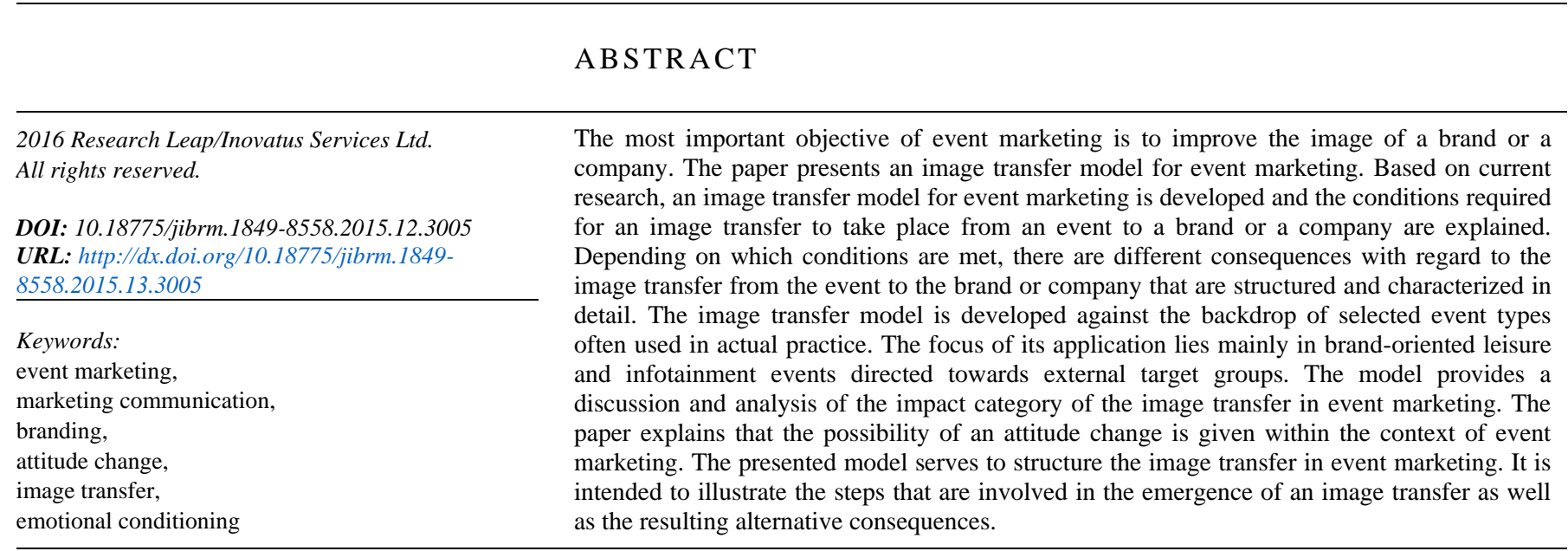

\section{Introduction}

"Consumers love events, corporations love consumers [...], this is a match made in heaven" (D'Alessandro, 1993). Events emotionalize the audience. Thus, a change in attitude or an image transfer respectively, constitutes a core objective or action quantity, which can be attained with the use of event marketing. This stems in particular from the fact that a high correlation is assumed to exist between the attitude towards or the image of a brand or a company and the actual purchasing behavior of consumers (Hätty, 1989).

Event marketing has established itself as an innovative nonclassical communications tool, which represents more than just a modern-day complement to the existing communications mix. The diverse areas of application and the potential of event marketing allow us to reach relevant target groups in terms of the current zeitgeist, generate brand-relevant realities and create experience worlds, engender popularity values and in this way to establish a bond between a brand or company and consumers (Nufer, 2015).

\section{Literature review}

\subsection{Definition of event marketing}

Marketing events are characterized by the fact that they generate something special or even unique with an event, enabling participants to experience the brand or the company. The intent of product, corporate or service-related events is to present cognitive, emotional and physical stimuli, trigger activation processes and communicate corporate-driven messaging, information and associations the purpose of which is to make a positive contribution to the establishment of corporate and brand values. Thus, marketing events are purposefully staged events or occurrences whose key goal is to convey experiences to participants or attendees. Events are communications media and can, in principle, can be utilized in the context of other communications tools (Jones, 2014; Kiel and Bäuchl, 2014; Raj et al., 2013; Bladen et al., 2012; Getz, 2012).

Following up on this, event marketing is to be understood as the targeted creation of such events within the framework of the planning and control process (Nufer and Bühler, 2015): "Event marketing is both an interactive and experience-oriented communications tool that serves the purposeful target group or scene-oriented production of specifically initiated events as well as their planning, execution and control within the context of integrated corporate communications." Event marketing entails the systematic planning, organization, execution and control of events as well as their meaningful incorporation in integrated corporate communications. Thus, event marketing is an independent (self-contained) communications tool.

By means of its constitutive attributes, event marketing can be clearly differentiated particularly from (event) sponsorship, as Table 1 shows. 
Table 1: Differentiation of event marketing from sponsorship

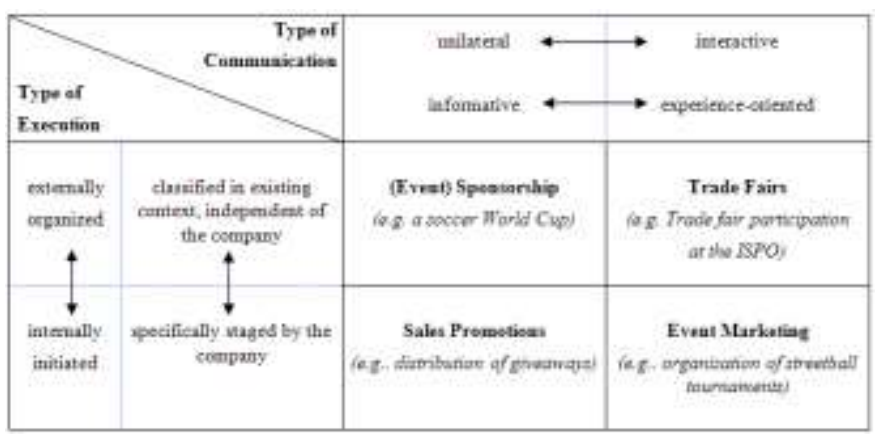

An essential communications feature of event marketing is its interaction orientation within the context of an experiencefocused strategy. On the one hand, its capacity for dialogue enables immediate personal contact with the target group, whereby scattering loss can be kept at relatively low levels. On the other hand, in contrast to sponsorship or sales promotions, those present can be addressed emotionally and actively involved in the event at the behavioral level. The autonomous implementation is an additional characteristic of event marketing. The event is initiated by the company itself, and other than in the case, for example, of sponsorship or trade fairs, it does not involve the use of an externally created framework as a presentation platform. The specifically self-staged brand world should come alive for the recipient of the messaging and it should lead to the consumer's emotional affinity to the brand.

\subsection{Objectives of event marketing}

Event marketing is primarily implemented to achieve the overall objective of emotionalizing the target group (Lasslop, 2003; Drengner, 2008; Nufer, 2015). That is why psychological communications objectives are paramount as detail objectives of event marketing. A priori, we can differentiate between affectiveoriented communications objectives and those that are cognitiveoriented. Thereby, the individual emphases are placed depending upon the event and the target group. This double dichotomization allows for categorizing psychological communications objectives inherent in event marketing into four groups, which are summarized and illustrated in Table 2 .

Table 2: Communications objectives of event marketing

\begin{tabular}{|c|c|}
\hline Affectively - oriented external zoaks & Cognieiveb-orimoted external goaks \\
\hline 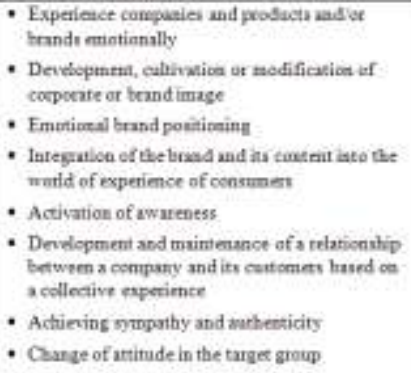 & 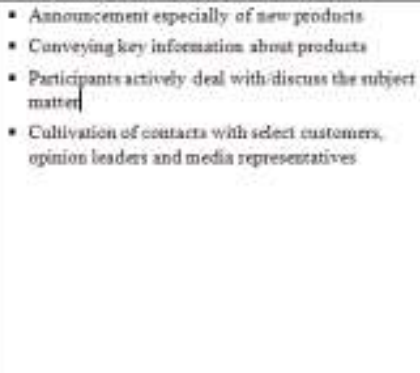 \\
\hline Affoctingh-ariented internal goath & Cognitively-eriented internal geath \\
\hline 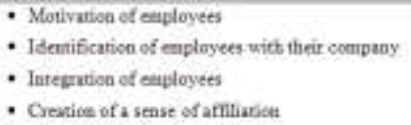 & $\begin{array}{l}\text { - Expertise } \\
\text { - Cominaing training } \\
\text { - Persouat capabilities } \\
\text { - Customer awareass }\end{array}$ \\
\hline
\end{tabular}

\subsection{Concept of the image transfer}

Zentes (1996) is one of the few to initially regard the concept of image transfer from a neutral perspective, without immediately concentrating on the specific areas of application of this phenomenon. He defines image transfer in the broadest sense of the term as "the transfer and reinforcement of object association between objects of different categories".

Based on this, Glogger (1999) formulates a marketing-specific conceptualization of the term image transfer:

- An image transfer is not a measure or action taken by a company, but rather a reaction in the psyche of persons that occurs in response to a measure or action of the company.

- The image transfer comprises not only the transfer of new associations that had not been linked with the object up to now, but also the reinforcement of already existing associations.

- Both connotative and denotative object associations can be transferred or reinforced.

- An image transfer is characterized by reciprocity, i.e. it can occur for two objects in both directions.

In the following we will revert to Glogger's definition. To further analyze an image transfer, it may be possible to undertake a nominally distinct separation of the involved objects from one another: While the master object represents the object of opinion that possesses the features to be transferred, one must understand the transfer object as the object of opinion to which these features are to be transferred or whose features are to be reinforced; the object associations that are transferred or reinforced ultimately represent the transfer content.

\subsection{Forms of image transfer in marketing}

Basically, an image transfer in marketing can manifest itself in two different forms: One must differentiate between an image transfer in product policy and an image transfer in communications policy. Although the actual transfer process is identical in both areas of the marketing mix, a differentiated consideration appears reasonable, not in the least due to their different underlying objectives. Whereas in product policy, there is a direct company-internal relationship between the master object and the transfer object and to some extent both are "dependent" upon one another, in the context of communications policy, the choice of an appropriate master object calls for resorting to an external object of opinion, i.e. one that is not part of the company, thus deemed "independent" (Mayer and Mayer, 1987; Glogger, 1999), The considerations in terms of communications policy with regard to the image transfer are largely based on the product policy-related problems. Figure 1 provides an overview of this. 


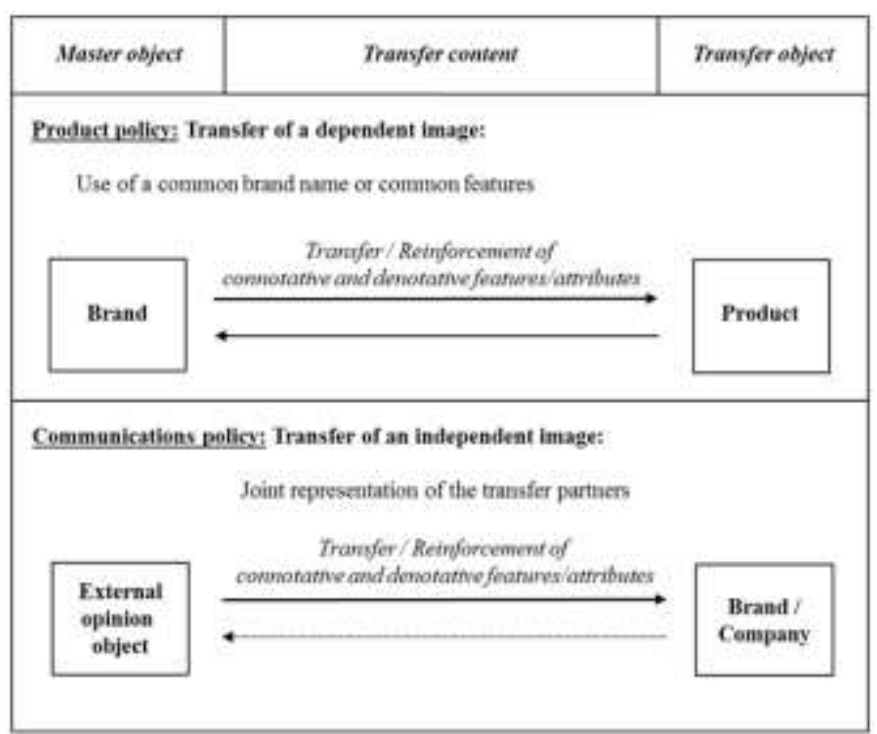

Figure 1: Forms of image transfer in marketing (based on: Glogger (1999))

\section{Image transfer model for event marketing}

\subsection{Emotional conditioning}

Emotional conditioning constitutes a special case of classical conditioning (Behrens, 1991). Advertising impact is frequently explained in terms of emotional conditioning processes: If a brand (conditioned stimulus) is repeatedly represented in conjunction with emotional stimuli (unconditioned stimuli), the original neutral brand takes on a similar emotionally positive significance (conditioned reaction) (Kroeber-Riel, 1993; Ghazizadeh, 1987; Meffert, 1992; Trommsdorff, 1998).

With regard to event marketing this means: The Unconditioned Stimulus (UCS), the marketing event, has the impact of a live experience, which is very intense due to its extended exposure time, generating fun and exhilaration as an Unconditioned Reaction (UCR) on the part of the participant. In this almost "euphoric mood", simultaneously with these emotions, the participant absorbs information about the company initiating the event or the brand (Conditioned Stimulus, CS). CS and UCR combine to form a new, conditioned reaction (Conditioned Reaction, CR) to the emotional charge of the company or the brand. Thus, the company or brand acquires the features of the experience value of the event (see Figure 2).

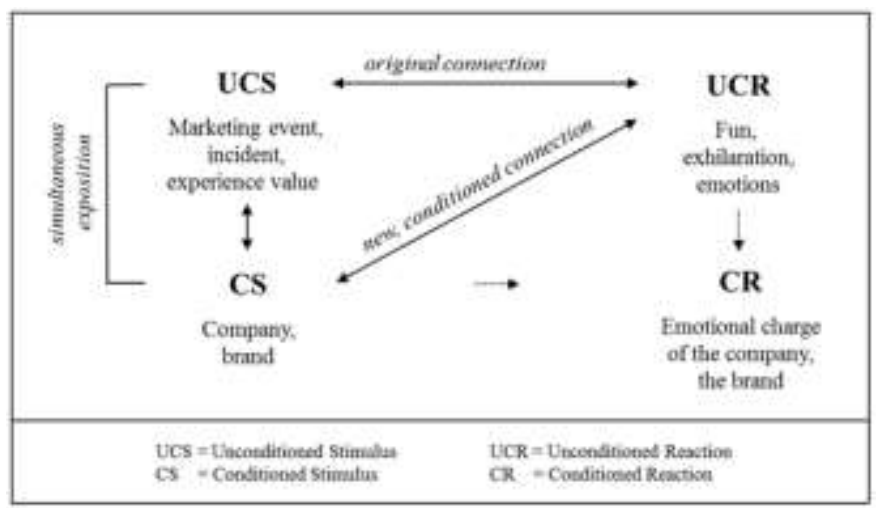

Figure 2: Emotional conditioning in event marketing (based on: Deimel (1992); Erdtmann (1989))

\subsection{Depiction of the image transfer model}

A marketing event is distinguished by the fact that the consumer is simultaneously presented with emotionally affective and informational cognitive stimuli, or that both connotative and denotative product and company features are conveyed. Both the event and the brand exude emotional and informative effects. However, the central function of the event is also to trigger emotions, whereas beyond that, the initiating company seeks primarily to convey information on the brand. The two transfer partners involved, the event (master object) and brand (transfer object) are presented together in the context of the event (Nufer, 2015). The additional coherences depicted in Figure 3 will be addressed in detail below.

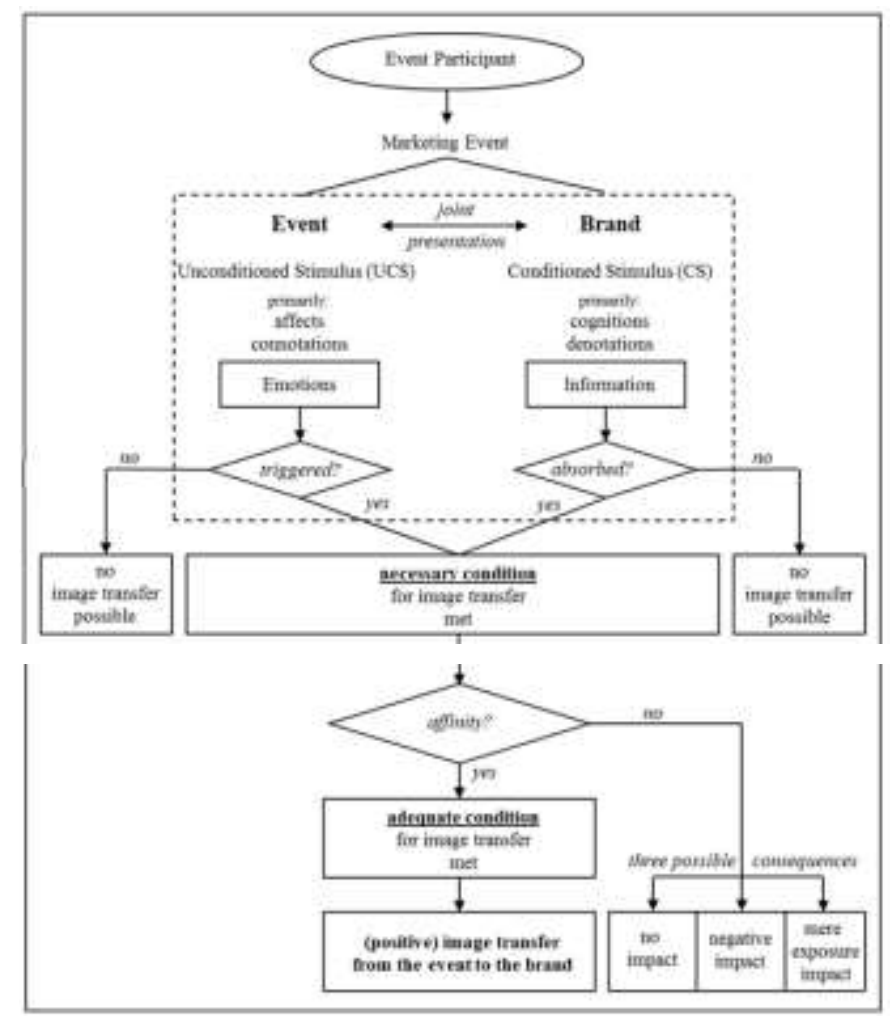

Figure 3: Image transfer model for event marketing

\subsection{Requirements for the occurrence of an image transfer}

The prerequisite (necessary condition) for the occurrence of an image transfer in event marketing is as follows: Experience values from the event and information about the brand must be simultaneously absorbed by the consumer/recipient. The requirement for uniform perception coherence, for instance, presents an obstacle that is not to be underestimated in sponsorship. If, for example, a spectator who is totally focused on an exciting soccer game takes no notice at all of the information positioned on the perimeters, the result is loss of coverage as a consequence of the unfulfilled necessary condition; in this case, the occurrence of an image transfer is impossible. However, since sponsorship involves the communicative usage of an externally, i.e. by the sponsoring company, initiated independent platform, the risk in this context is far greater than it is for event marketing. In terms of the definition used, marketing events are internally initiated and staged and it is precisely for 
this reason that they provide the organizing company with very many more opportunities for action, to present itself in such a way that in addition to the emotions triggered by the event, the (voluntary) event participant absorbs information concerning the company or the brand.

In conjunction with testimonial advertising, the literature on the subject often stipulates that the relationship between the master object and transfer object should be "credible" (Hermanns, 1997; Bruhn, 1997; Erdtmann, 1989; Rieger, 1994). Psychologists have also acknowledged the necessity of an association between an unconditioned and a conditioned stimulus. Thus, for instance, von Rosenstiel (1979) remarks that "a totally arbitrary coherence of stimuli - in our case of products and specific emotions would hardly be possible". However, this affinity between the event and the brand cannot be a mandatory requirement for every event marketing commitment. Furthermore, an optimal (not maximum) measure of affinity should be aspired to. Therefore, in Figure 4 this condition for the occurrence of an image transfer is not classified as necessary in every case, but only as an additional requirement (adequate condition).

\subsection{Possible consequences}

The unfavorable constellation exists, when an event is incapable of triggering emotions with the participant and/or the consumer on site at the event does not acquire any information on the brand or the initiating company. The occurrence of an image transfer in such a case is out of the question.

If the consumer does absorb emotions and information together, but there is insufficient affinity between the event and the brand or the consumer does not accept the (artificially) constructed connections between the event and the brand, basically three different consequences are possible:

- There is no resulting image effect whatsoever (i.e. neither positive nor negative).

- A negative effect arises.

- Under certain conditions a conditioning achievement is nevertheless conceivable (that must be differentiated from an image transfer effect).

In a case where sufficient affinity does not exist from the point of view of the consumer, the event-initiating company incurs a decisive disadvantage: It cannot rely on already existing associative connections but rather must establish these itself quasi-artificially. Under these circumstances learning processes proceed in a more cumbersome and inefficient manner than if one can fall back on already existing associations (Erdtmann, 1989). In extreme cases, it must be feared that no image effect at all will result.

If there is no connection to the company or the brand, i.e. an event marketing commitment is perceived as not credible or inappropriate, there is a real risk of adverse reactions on the part of consumers. In this regard Erdtmann (1989) discusses a fictitious "spectrum of individual misfit acceptance", which implies that conditioning processes that take place when there is no affinity, as of a certain level they turn into "misfit" and may produce the opposite effect with consumers. Thus, what we have here is reactance phenomenon. Reactance designates a motivational state of stress which appears when a person perceives a threat to his or her scope of free choice (Mayer, Däumer and Rühle, 1982). Such cases may result in the rejection of a change in attitude or even to a backlash. If a company orchestrates an event at which its target group address is designed to be so heavily influential that even an existing level of tolerance among participants is exceeded and, in addition, any natural relationship between the event and the brand are missing, theoretically, the consequence may be that reactance also develops for event marketing, culminating in the risk of a negative transfer. Sports sponsorship has already provided numerous examples of thus related risks extending to negative image transfer: Several years ago, main and jersey sponsor TV Spielfilm terminated its sponsorship contract with its sponsorship partner Hamburger SV in the middle of the season due to a series of losses, fearing a negative association. Another example was the scandal involving the designated coach of the national team and Christoph Daum. Accused of cocaine use, he not only lost his position as coach at Bayer Leverkusen after a hair analysis proved positive and the prospective job at the DFB (slogan: "no power to drugs"), but also was terminated for the advertising contract with the RWE Group (Avanza brand), which felt unable to continue with an image campaign with Daum as its focal point.

Even if the consumer does not perceive a corresponding affinity between the event and the brand, the coincidence of stimuli at the same time can already suffice to produce a conditioning achievement, i.e. for the establishment of a conditional reaction. The mere exposure to the advertising stimuli already creates the basis for a positive change in attitude. A high number of contacts with a stimulus could possibly result in a familiarization or acceptance effect with the consumer. It can be assumed that some companies are aware of this (one-dimensional) benefit and are content with it. This is the only way that the objective of increased awareness, which in event marketing is basically rather minor in theory yet prevails in practice can be reproduced (Erdtmann, 1989). That being said, the benefits of mere exposure effects must be differentiated from an image transfer effect as described above, since in this case no cognitive examination (or analysis) of the engineered connection between the master object and the transfer object takes place, but merely familiarization with connections constructed between the event and the brand. For instance, in the event series "Street Soccer Cup" initiated by the supermarket chain real, the fit between brand/company and event tends to be too insignificant to achieve an image transfer effect.

The ideal case of a positive image transfer of an event to a brand or company comes about when emotions are triggered by an event, information about the brand/company is absorbed AND the consumer (recipient) accepts the link connecting the event and the brand/company, i.e. optimal affinity exists. In terms of the psychology of memory, such links are based on associations: A declining stratification of associative structures (reticular links, semantic networks) implies a reduction in the distance between two points of association, which in principle entails an increase in the potential for association(s) (Hätty, 1989).

\subsection{Limitations and critical assessment}

This model provides a discussion and analysis of the impact category of the image transfer in event marketing. The study 
makes it clear that in principle the possibility of an image transfer is given within the context of event marketing. However, its implementation requires taking various conditions into consideration. The transfer model that is developed serves to structure the image transfer in event marketing. In particular, it is intended to illustrate the steps that are involved in the emergence of an image transfer as well as the resulting alternative consequences.

Due to the diverse forms of event marketing, there can be no universally valid image transfer model. The model was developed against the backdrop of selected event types often used in actual practice. The focus of its application lies mainly in brand-oriented leisure and infotainment events directed towards external target groups. To date, not all links have been empirically reviewed. Nevertheless, the model does go beyond the practice-oriented statements specifically related to individual cases that have frequently been found in the literature on event marketing and can be viewed as a typological approach.

The assumptions or hypotheses expressed can be designated as plausible, to some extent as proven: The hypotheses are plausible inasmuch as they are substantiated based on their reference to secured knowledge. On the other hand, the considerations that have already been empirically confirmed in various studies are said to be proven.

\section{Conclusions}

An image transfer from an emotionally charged event to a brand or company represents one of the most important objectives of event marketing. The thoughts presented above have shown that achieving an image transfer with event marketing is basically possible. The use of event marketing seeks to shorten the distance between the actual and target image of a brand or company by effecting a transfer of the emotions conveyed by the event to the brand. The better the fit of the event with the brand, the more likely the success of conferring a distinctive (unmistakable) image on a brand or company by transferring its emotional associations.

In comparing event marketing with classic communications tools such as advertising, it is clear that effectiveness research on the subject is still in its early stages. Therefore, this paper can only represent a first step towards the analysis of the effectiveness of event marketing. Effectiveness research, especially with regard to the effect that marketing events have on image is far from being completed.

\section{References}

Behrens, G. (1991), Konsumentenverhalten. Entwicklung, Abhängigkeiten, Möglichkeiten, 2nd ed., Physica, Heidelberg.

Bladen, C., Kennell, J., Abson, E. and Wilde, N. (2012), Events Management - An Introduction, Routledge, London.

Bruhn, M. (1997), Kommunikationspolitik. Bedeutung Strategien - Instrumente, Vahlen, München.

D'Alessandro, D. F. (1993), "Event Marketing: The Good, The Bad \& the Ugly", Vital Speeches of the Day, Vol. 59, No. 16, pp. 503-507.

Deimel, K. (1992), Wirkungen der Sportwerbung. Eine verhaltenswissenschaftliche Analyse, Peter Lang, Frankfurt/Main.

Drengner, J. (2008), Imagewirkungen von Eventmarketing. Entwicklung eines ganzheitlichen Messansatzes, 3rd ed., Deutscher Universitäts Verlag, Wiesbaden.

Erdtmann, S. L. (1989), Sponsoring und emotionale Erlebniswerte. Wirkungen auf den Konsumenten, Deutscher Universitäts Verlag, Wiesbaden.

Getz, D. (2012), Event Studies - Theory, Research and Policy for Planned Events, 2nd ed., Routledge, London.

Ghazizadeh, U. R. (1987), Werbewirkung durch emotionale Konditionierung. Theorie, Anwendung und Meßmethode, Peter Lang, Frankfurt/Main.

Glogger, A. (1999), Imagetransfer im Sponsoring. Entwicklung eines Erklärungsmodells, Peter Lang, Frankfurt/Main.

Hätty, H. (1989), Der Markentransfer, Physica, Heidelberg.

Hermanns, A. (1997), Sponsoring. Grundlagen, Wirkungen, Management, Perspektiven, 2nd ed., Vahlen, München.

Jones, M. (2014), Sustainable Event Management - A Practical Guide, 2nd ed., Routledge, London.

Kiel, H.-J. and Bäuchl, R. G. (2014), Event-Management. Konzeption, Organisation, Erfolgskontrolle, Vahlen, München.

Kroeber-Riel, W. (1993), Strategie und Technik der Werbung. Verhaltenswissenschaftliche Ansätze, 4th ed., Kohlhammer, Stuttgart.

Lasslop, I. (2003), Effektivität und Effizienz von MarketingEvents. Wirkungstheoretische Analyse und empirische Befunde, Deutscher Universitäts Verlag, Wiesbaden.

Mayer, A. and Mayer, R. U. (1987), Imagetransfer, Spiegel, Hamburg.

Mayer, H., Däumer, U. and Rühle, H. (1982), Werbepsychologie, Schäffer-Poeschel, Stuttgart.

Meffert, H. (1992), Marketingforschung und Käuferverhalten, 2nd ed., Gabler, Wiesbaden.

Nufer, G. (2015), "Creating an Image Transfer through Event Marketing: Principles, Requirements and Consequences", European Journal of Business and Social Sciences, Vol. 3, No 12, pp. 1-18.

Nufer, G. and Bühler, A. (2015), Event-Marketing in Sport und Kultur. Konzepte - Fallbeispiele - Trends, Erich Schmidt Verlag, Berlin. 
Raj, R., Walters, P. and Rashid, T. (2013), Events ManagementPrinciples \& Practice, 2nd ed., Sage Publications, London.

Rieger, J. (1994), Sponsoring als Instrument der Imagepolitik im Investitionsgüterbereich, doctoral dissertation, Freie Universität Berlin, Berlin.

Trommsdorff, V. (1998), Konsumentenverhalten, 3rd ed., Kohlhammer, Stuttgart u.a.

Von Rosenstiel, L. (1979), "Produktdifferenzierung durch Werbung", Marketing Zeitschrift für Forschung und Praxis, Vol. 2, No. 3, pp. 151-164.

Zentes, J. (1996), Grundbegriffe des Marketing, 4th ed., Schäffer-Poeschel, Stuttgart. 